\title{
Daily air pollution levels and acute asthma in southern Sweden
}

\author{
B. Forsberg*‡, N. Stjernberg**†, R. Linné\#, B. Segerstedt $\$$, S. Wall
}

\begin{abstract}
Daily air pollution levels and acute asthma in southern Sweden. B. Forsberg, N. Stjernberg, R. Linné, B. Segerstedt, S. Wall. @ERS Journals Ltd 1998.

ABSTRACT: This study aimed to investigate the association between daily air pollution levels and the occurrence of acute respiratory signs and symptoms among people with asthma or asthma-like problems.

Thirty eight subjects in the southern Swedish city of Landskrona kept a daily diary for 10 weeks. The daily prevalence of symptoms, supplementary bronchodilator use and peak flow deviations were compared with measurements of environmental nitrogen dioxide $\left(\mathrm{NO}_{2}\right)$, sulphur dioxide, temperature and humidity in the city.

The occurrence of severe asthma, both during the day and during the evening, was significantly positively associated with the concurrent $24 \mathrm{~h}$ average concentration of $\mathrm{NO}_{2}$, which never exceeded $72 \mu \mathrm{g} \cdot \mathrm{m}^{-3}$. A correlation of borderline significance was found between the use of on-demand medication and the $\mathrm{NO}_{2}$ level. However, peak flow deviations were not associated with air pollution or weather conditions, which may be explained by the beneficial effect of bronchodilators used by 28 of the subjects.

The results of this study confirm those of some earlier studies and suggest that aggravation of asthma is related to daily variations in air quality, as indicated by relatively low ambient concentrations of nitrogen dioxide. These results also indicate that it may be appropriate to examine severe asthma symptoms separately. Eur Respir J 1998; 12: 900-905.
\end{abstract}

Depts of *Environmental Health and demiology and Public Health and $\$$ School of Business, Umeå University, Umeå, Sweden. **National Institute for Working Life, Umeå, Sweden. \#Landskrona Hospital, Landskrona, Sweden.

Correspondence: B. Forsberg, Dept of Environmental Health, Umeå University, S90187 Umeå, Sweden. Fax: 4690135636

Keywords: Air pollution, asthma, nitrogen dioxide, peak flow, respiratory

Received: October 211997

Accepted after revision June 251998

Supported financially by the Swedish Asthma and Allergy Foundation, The Centre for Environmental Research in Umeå (CMF) and the Environmental Health Office in Landskrona.

$\dagger$ : Deceased
Asthmatics have been shown to be greatly affected by environmental exposure. Both experimental [1] and epidemiological studies [2] have shown air pollution to aggravate asthma problems. Concern about the possible adverse respiratory effects of major ambient air pollutants has stimulated investigators to attempt to relate effects to lower and lower concentrations in the search for minimum concentrations at which adverse effects on health are detectable. As a result of such studies, even in relatively weakly polluted areas, the guidelines and limits for several pollutants are now under revision and acceptable limits from a health point of view are expected to be set at increasingly lower levels.

Daily diaries of respiratory health are very useful in studies of the effects of air pollution on susceptible persons, particularly in smaller cities and towns where studies of hospitalization or mortality would provide very small numbers. Diary studies, which are often referred to as panel studies, have become common in the study of air pollution and respiratory effects [2-4]. Diary information includes health-related endpoints such as exacerbations of asthma, other symptoms, peak flow and airway medication in different combinations [3-10]. Environmental data must include not only air pollution levels but also factors that could operate as confounders. One advantage of the diary studies is that potential confounders are limited to those that can co-vary with ambient pollution concentrations over time, e.g. humidity, temperature and pollen concentrations. The typical confounding factors from crosssectional studies, such as socioeconomic status and smoking habits, do not pose any problems in these studies.
Analysis of frequencies of symptoms and medication use can be based on time series of diary data from individuals in a panel or averaged daily prevalence or incidence rates for the panel. Regardless of the method used, it is necessary to address the problem of state dependence in the health variables to avoid underestimation of the standard error for the parameter estimates [5]. If a person has a symptom one day, they will probably present with the same symptom the next day, which accounts for the relatively frequent occurrence of autocorrelation of daily prevalences. A problem with averaged symptom data is the occurrence of missing responses or exclusions due to time spent outside the study area, which leads to daily prevalences based on a varying panel composition, without any relevant adjustments.

This report presents data from a study of acute respiratory problems among people with asthma or asthma-like problems and their relation to variations in low air pollution concentrations in the southern Swedish city of Landskrona, which has a relatively mild winter climate.

\section{Methods}

\section{Study population}

Landskrona is a city on the coast in southern Sweden with approximately 30,000 residents. It is situated close to several larger cities. The air in Landskrona is affected by emissions from traffic on a major highway and emissions from local industries such as a fertilizer plant with its 
nitrogen emissions. This region is also affected by transported pollutants, mainly from the south. The levels of nitrogen dioxide and sulphur dioxide are, therefore, higher than in most Swedish cities of a similar size [11].

The study panel of asthmatics was recruited through advertisements in local newspapers. Thirty-eight volunteers aged Š15 yrs and residing in Landskrona, who were prepared to keep a symptom diary, were included in the study. Patient records from the local hospital and primary healthcare centres and peak expiratory flow (PEF) curves from the study were used to characterize the panel members. Subjects with a typical asthma history, including attacks of shortness of breath and wheezing or waking during the night with shortness of breath, were considered to be asthmatics even if no tests had been made to verify the diagnosis. Other criteria for asthma classification in this study were a PEF variability of at least $20 \%$ within $24 \mathrm{~h}$, or a lung function reversibility of at least $15 \%$, measured using spirometry. With these criteria, 33 subjects were asthmatics. The remaining five subjects presented with less typical histories, but they reported severe episodic airway problems with asthma-like symptoms, such as dry cough apart from colds. All 38 subjects were included in the analyses. Twenty eight of the subjects used on-demand medication (bronchodilators as needed) and 23 were on inhaled steroids.

\section{Health measurements}

The panellists completed a daily report on each day of the 70-day study period (18 January-27 March), including the presence and severity of asthma symptoms (none or light, marked or severe asthma during the day and during the evening), on-demand medication (supplementary bronchodilators), morning and evening peak flow and time spent away from the city. Severe asthma was defined as unusually severe for the person in question. PEF was measured in the home using a MiniWright peak flow meter. Participants were instructed to perform the PEF measurements at the same time every day, before breakfast and before going to bed, in both cases before any medication was taken. Every measurement was repeated three times, and all three values were noted in the diary and the largest value was used in the statistical analyses.

\section{Exposure information}

Above-roof-level concentrations of air pollution were measured continuously during the study period at a central monitoring station in an area with heavy traffic. $\mathrm{NO}_{2}$ and $\mathrm{SO}_{2}$ were measured with the differential optical ab-sorption spectroscopy (DOAS) technique (OPSIS) over three blocks (approximately $100 \times 100 \mathrm{~m}$ ). This method was developed by Platt and Perner [12] and meets the requirements of the US Environmental Protection Agency and many other authorities. Daily average relative humidity and temperature values were obtained from the nearest national weather station, approximately $1 \mathrm{~km}$ east of the air pollution measurement site.

\section{Statistical analysis}

If a subject had spent more then $6 \mathrm{~h}$ between 07:00 and 19:00 $\mathrm{h}$ outside Landskrona town, their data for that day were excluded from the analysis. The daily values for the dependent variables were, therefore, based on different numbers of subjects. The daily averages for these variables can, thus, also vary depending on the panel composition. In the present study, 2,382 subject-days of diary information, corresponding to $90 \%$ of the maximum potential number, were included in the analyses.

The analysis of prevalence rates from daily diaries is complicated not only be the dependencies among responses of the same subject on different days (heterogeneity in the panel), but also by the dependencies among responses on successive days. These factors have been taken into account with several different approaches $[3,5]$. In the present study, five binary health outcome variables have been analysed using logistic regression (SPSS for PC; SPSS Inc., Chicago, IL, USA) with models which include not only environmental variables but also separate intercepts for each individual (to model heterogeneity in the data), the subject's symptoms status on the previous day (to model autocorrelation in prevalence) and the day order of study (to model linear time trends). The daily (24 h) average concentrations of $\mathrm{NO}_{2}$ and $\mathrm{SO}_{2}$, daily mean relative humidity and temperature were included in the models, together with their one day lags.

$\mathrm{PEF}$ was analysed with multiple linear regression of the daily population average peak flow deviation on the independent variables [6]. The means for the morning and the evening PEF for each subject during the study were first calculated. Individual deviations of daily performance from each subject's mean PEF were then calculated and averaged across the participants to obtain daily mean devations $(\triangle \mathrm{PEF})$ for the morning and the evening PEF. In order to correct for different daily sample size, the least squares regressions were made weighted using the number of subjects on each day as weights. The models were adjusted for autocorrelation by incorporating a first-order autoregressive component. The day order of study and environmental variables was included as in the logistic models. Morning PEF was analysed only for relations to the previous-day environmental situation.

\section{Results}

The $24 \mathrm{~h}$ average concentrations of $\mathrm{NO}_{2}$ and $\mathrm{SO}_{2}$, as well as the average relative humidity and temperature, are presented in table 1 together with the minimum and maximum values. There were no missing values during the study period. Over the 10 week study period there was no trend in pollution concentrations, but the temperature increased slightly during the study. The correlations among these environmental variable are presented in table 2 . Significant correlations were found between the two pollutants and relative humidity, and between the pollutants $(\mathrm{p}<0.01)$. Neither air pollution levels nor relative humidity were significantly correlated with temperature.

Table 1. - Distribution of air pollution, temperature and relative humidity $(\mathrm{RH})$

\begin{tabular}{lrrrr}
\hline $\begin{array}{l}\text { Variable } \\
24 \mathrm{~h} \text { average }\end{array}$ & Mean & Minimum & Maximum & SD \\
$\mathrm{NO}_{2} \mu \mathrm{g} \cdot \mathrm{m}^{-3}$ & 30.5 & 5.7 & 71.7 & 13.3 \\
$\mathrm{SO}_{2} \mu \mathrm{g} \cdot \mathrm{m}^{-3}$ & 13.6 & 5.2 & 65.0 & 9.4 \\
$\mathrm{RH} \%$ & 81.0 & 51.0 & 92.0 & 7.6 \\
Temperature ${ }^{\circ} \mathrm{C}$ & 3.2 & -3.7 & 6.4 & 2.3 \\
\hline
\end{tabular}


Table 2. - Pearson correlation coefficients for air pollution, temperature and relative humidity $(\mathrm{RH})$

\begin{tabular}{lllll}
\hline $\begin{array}{l}\text { Variable } \\
\text { 24 h average }\end{array}$ & $\mathrm{NO}_{2}$ & $\mathrm{SO}_{2}$ & $\mathrm{RH}$ & $\begin{array}{c}\text { Tempera- } \\
\text { ture }\end{array}$ \\
\hline $\mathrm{NO}_{2}$ & 1.0 & & & \\
$\mathrm{SO}_{2}$ & $0.52^{* *}$ & 1.0 & & \\
$\mathrm{RH}$ & $0.60^{* *}$ & $0.31^{* *}$ & 1.0 & \\
Temperature & -0.06 & -0.06 & 0.23 & 1.0 \\
\hline$* *$ p $<0.01$. & & & &
\end{tabular}

\section{Symptoms and medication}

No trends over time were observed in frequency or severity of asthma symptoms or the use of on-demand medication. The mean daily prevalences were $30 \%$ for any asthma symptoms (marked or severe) during the day, $28 \%$ for any asthma symptoms during the evening and $29 \%$ for the use of on-demand medication. The mean daily prevalence of severe asthma symptoms was $2 \%$ for both days and evenings.

The $\beta$-coefficients from the logistic regression analyses are presented in table 3 . Severe asthma both during the day and during the evening was significantly positively associated with the concurrent $24 \mathrm{~h}$ average concentration of $\mathrm{NO}_{2}$ at the monitoring station. An increase in the $\mathrm{NO}_{2}$ concentration of $10 \mu \mathrm{g} \cdot \mathrm{m}^{-3}$ was based on the coefficients, associated with adjusted odds ratios of 1.5. Figure 1 shows the temporal pattern of daily mean values of $\mathrm{NO}_{2}$ and the prevalences of any asthma symptoms and of severe asthma symptoms. A correlation of borderline significance existed between the use of on-demand medication and the $\mathrm{NO}_{2}$ average on the same day. The use of medication was negatively associated with the mean temperature on the previous day. If a subject reported a positive response on the previous day, the probability for that res- ponse increased significantly on the following day, with odds ratios in the order of 3.0-4.7 for the five dependent variables shown in table 3.

As a test for remaining autocorrelation, residuals were aggregated over all subjects for each day and analysed. No significant autocorrelation existed for lag 1-16 in any model. The first-order autocorrelation for severe asthma during the day and during the night gave correlation coefficients of 0.02 and 0.04 , respectively.

All analyses have been repeated after exclusion of the five subjects who did not meet the criteria for asthma. The results were almost identical, with the same associations being significant as for the entire panel.

\section{Peak flow}

The morning $\triangle \mathrm{PEF}$ increased slightly over time during the study, but it was not significantly related to the environmental conditions on the previous day (table 4). The evening $\triangle \mathrm{PEF}$ was not significantly associated with air pollution or weather conditions on either the concurrent or the previous day. Exclusion of the five subjects with only asthma-like symptoms did not change these results and the results were almost identical for models without weights and the autoregressive component.

The relation of the evening $\triangle \mathrm{PEF}$ to the prevalences of asthma symptoms during the same day and evening and the use of on-demand medication was also analysed. Only the correlation with the prevalence of any asthma symptoms during the evening was significant $(\mathrm{r}=-0.32, \mathrm{p}<0.01)$. There was no correlation $(\mathrm{r}=0.05)$ between the evening $\triangle \mathrm{PEF}$ and the prevalence of on-demand medication, while the use of medication was associated with both asthma symptoms during the day $(\mathrm{r}=0.39, \mathrm{p}<0.01)$ and during the

Table 3. - $\beta$-Coefficients of the logistic regression analysis for asthma symptoms during the day and during the evening and for on-demand medication

\begin{tabular}{|c|c|c|c|c|c|}
\hline \multirow[t]{2}{*}{ Variable } & \multicolumn{2}{|c|}{ Day } & \multicolumn{2}{|c|}{ Evening } & \multirow{2}{*}{$\frac{\text { Day or evening }}{\begin{array}{c}\text { On-demand } \\
\text { medication }\end{array}}$} \\
\hline & $\begin{array}{c}\text { Any } \\
\text { asthma }\end{array}$ & $\begin{array}{l}\text { Severe } \\
\text { asthma }\end{array}$ & $\begin{array}{c}\text { Any } \\
\text { asthma }\end{array}$ & $\begin{array}{l}\text { Severe } \\
\text { asthma }\end{array}$ & \\
\hline \multicolumn{6}{|c|}{ Concurrent $24 \mathrm{~h}$ average } \\
\hline \multirow[t]{2}{*}{$\mathrm{NO}_{2}$} & 0.0077 & $0.0410 *$ & 0.0086 & $0.0430 * *$ & 0.0113 \\
\hline & $(0.0067)$ & $(0.0168)$ & $(0.0070)$ & $(0.0164)$ & $(0.0066)$ \\
\hline \multirow[t]{2}{*}{$\mathrm{SO}_{2}$} & -0.0100 & -0.0349 & 0.0023 & 0.001 & 0.0019 \\
\hline & $(0.0081)$ & $(0.0311)$ & $(0.0078)$ & $(0.0179)$ & $(0.0076)$ \\
\hline \multirow[t]{2}{*}{ RH } & -0.0004 & -0.0150 & 0.0071 & 0.0055 & -0.0019 \\
\hline & $(0.0120)$ & $(0.0313)$ & $(0.0127)$ & $(0.0349)$ & $(0.0118)$ \\
\hline Temperature & $\begin{array}{c}0.0084 \\
(0.0484)\end{array}$ & $\begin{array}{l}-0.0921 \\
(0.1262)\end{array}$ & $\begin{array}{l}-0.0133 \\
(0.0508)\end{array}$ & $\begin{array}{c}0.0186 \\
(0.1412)\end{array}$ & $\begin{array}{c}0.0271 \\
(0.0477)\end{array}$ \\
\hline \multicolumn{6}{|c|}{ Previous day $24 \mathrm{~h}$ average } \\
\hline \multirow[t]{2}{*}{$\mathrm{NO}_{2}$} & 0.0064 & 0.0075 & -0.0002 & -0.0094 & 0.0023 \\
\hline & $(0.0069)$ & $(0.0180)$ & $(0.0073)$ & $(0.0185)$ & $(0.0068)$ \\
\hline \multirow[t]{2}{*}{$\mathrm{SO}_{2}$} & -0.0029 & $-0.0264)$ & -0.0052 & 0.0074 & -0.0093 \\
\hline & $(0.0077)$ & $(0.0287)$ & $(0.0081)$ & $(0.0171)$ & $(0.0080)$ \\
\hline \multirow[t]{2}{*}{ RH } & 0.0045 & 0.0130 & 0.0104 & 0.0058 & 0.0003 \\
\hline & $(0.0818)$ & $(0.0310)$ & $(0.0123)$ & $(0.0337)$ & $(0.0114)$ \\
\hline \multirow[t]{2}{*}{ Temperature } & -0.0430 & 0.0281 & -0.0447 & -0.0629 & $-0.0939 *$ \\
\hline & $(0.0464)$ & $(0.1243)$ & $(0.4883)$ & $(0.1289)$ & $(0.0457)$ \\
\hline \multirow[t]{2}{*}{ Day number } & -0.0017 & 0.0107 & -0.0033 & 0.0115 & -0.0012 \\
\hline & $(0.0042)$ & $(0.0106)$ & $(0.0043)$ & $(0.0122)$ & $(0.0041)$ \\
\hline \multirow{2}{*}{$\begin{array}{l}\text { Yesterday's condition } \\
\text { positive }\end{array}$} & $1.0901 * * *$ & $1.4875 * * *$ & $1.4620 * * *$ & $1.5479 * * *$ & $1.3780 * * *$ \\
\hline & $(0.1361)$ & $(0.4225)$ & $(0.1395)$ & $(0.4304)$ & $(0.1323)$ \\
\hline
\end{tabular}

Data are shown as $\beta$-coefficients (SEM). RH: relative humidity. *: $\mathrm{p}<0.05 ; * *: \mathrm{p}<0.01 ; * * *$ : $\mathrm{p}<0.001 ;{ }^{*}: \mathrm{p}=<0.1$. 


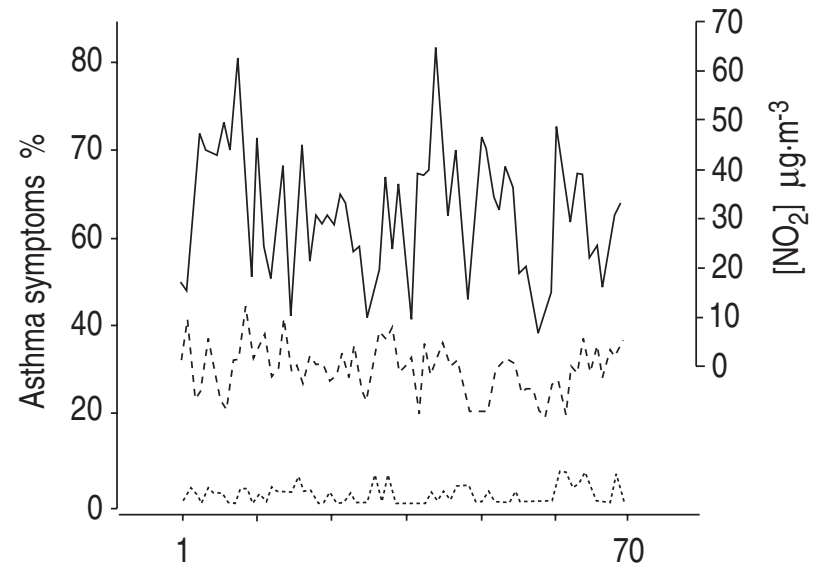

Fig. 1. - Daily concentrations (24 h) of nitrogen dioxide (—) and the prevalence of asthma symptoms: any (- - - ); or severe (-------) during the day plotted for the entire study period.

evening $(\mathrm{r}=0.46, \mathrm{p}<0.01)$. In addition, at the individual level nine subjects on average showed better evening PEF values on days when the use of on-demand medication was reported.

\section{Discussion}

In this study no significant association was found between asthma symptoms and air pollution when the symptom variables were transformed to binary variables (any asthma during the day and during the evening, respectively). However, significant correlations existed between the prevalence of severe asthma symptoms during the day and the evening and the daily $\mathrm{NO}_{2}$ concentration. These results indicate that air pollution and the severity of symptoms should be further studied with diary data. There was also a positive correlation, although not quite significant, between the use of on-demand medication and daily $\mathrm{NO}_{2}$ levels, but no short-term relation between peak flow and air pollution. The evening population peak flow deviation was not correlated to the daily prevalence of on-demand medication. The absence of such a correlation may be ex-

Table 4. - Regression coefficients for daily mean deviation in peak expiratory flow $\left(\triangle \mathrm{PEF} ; \mathrm{L} \cdot \mathrm{min}^{-1}\right)$ in the morning and evening in relation to environmental conditions

\begin{tabular}{lcccc}
\hline Variable & $\begin{array}{c}\text { Morning } \\
\Delta \text { PEF }\end{array}$ & \multicolumn{2}{c}{$\begin{array}{c}\text { Evening } \\
\text { PEEF }\end{array}$} \\
\hline Concurrent day & & & & \\
24 h average & & & & \\
$\mathrm{NO}_{2}$ & $\mathrm{NI}$ & -0.0236 & $(0.0639)$ \\
$\mathrm{SO}_{2}$ & $\mathrm{NI}$ & -0.0856 & $(0.0764)$ \\
$\mathrm{RH}$ & $\mathrm{NI}$ & -0.0556 & $(0.1148)$ \\
Temperature & $\mathrm{NI}$ & 0.3072 & $(0.4900)$ \\
Previous day & & & & \\
$24 \mathrm{~h}$ average & & & & \\
$\mathrm{NO}_{2}$ & 0.0636 & $(0.0561)$ & 0.0261 & $(0.0662)$ \\
$\mathrm{SO}_{2}$ & 0.0601 & $(0.0666)$ & 0.0660 & $(0.0774)$ \\
$\mathrm{RH}_{\mathrm{Temperature}}$ & -0.1351 & $(0.0947)$ & -0.0689 & $(0.1147)$ \\
Day number & -0.3287 & $(0.3123)$ & -0.1920 & $(0.4578)$ \\
$\mathrm{AR} 1$ & $0.0730 *$ & $(0.0354)$ & 0.0717 & $(0.0698)$ \\
\hline
\end{tabular}

Data are shown as $\beta$-coefficients (SEM). RH: relative humidity; NI: not included; AR1: regression coefficients for the first order autoregressive error. *: $\mathrm{p}<0.05 ; * * * \mathrm{p}<0.001$. plained by the beneficial effect of bronchodilator use, as about one-third of the users had a better mean evening PEF on days when on-demand medication was used. Since the bronchodilator question was dichotomous, no medication score (e.g. number of puffs) could be constructed. The phenomenon of a better pulmonary function on days with higher drug intake has previously been reported in a study from Toronto [7], resulting in a biased positive correlation between daily particulate pollution and lung function. Other studies have also shown associations between medication use and air pollution, which may have confounded or weakened the association between air pollution and PEF [6-9]. Presumably for the same reason, no correlation between PEF and environmental variables was found in a diary study of asthmatics from northern Sweden, despite the fact that severe shortness of breath was correlated with environmental variables [8]. A reduction in PEF related to air pollution in Paris was found only in a subgroup of mild asthmatic children with no regular asthma medication [10].

In studies of $\mathrm{NO}_{2}$ exposure via ambient air, measurements have usually been used from stations selected to reflect the city background concentrations rather than roadside levels. This means that the actual exposure to $\mathrm{NO}_{2}$ and traffic-related pollution is higher close to busy streets, where most people spend limited time, and generally lower indoors, where people spend most of their time. For persons who live in houses with gas appliances or kerosene heaters, these sources could be the main contributor to the total $\mathrm{NO}_{2}$ exposure $[13,14]$. However, in Landskrona gas is not used for cooking or heating of homes.

The outdoor level of $\mathrm{NO}_{2}$ is often used as an indicator for traffic pollution and, in such situations, it is likely that there are co-pollutants, e.g. particulates from diesel vehicles, which could contribute to the occurrence of respiratory problems. The composition of the pollution mixture may vary from place to place and time to time, depending on the source pattern. In this study it was also intended to use daily measurements of black smoke concentrations from a central monitoring station located in Landskrona as a part of the Swedish urban air pollution monitoring network. However, owing to a technical failure, no such data were available and, as a result, it was not possible to determine whether or not particulates affected the results. However, an analysis of more than 600 days of parallel measurements in central Landskrona showed a stronger correlation between black smoke and $\mathrm{SO}_{2}(\mathrm{r}=0.53)$ than between black smoke and $\mathrm{NO}_{2}(\mathrm{r}=0.39)$. Thus, if the environmental effects on severe asthma symptoms and medication were mainly due to variations in black smoke levels, the correlations with $\mathrm{SO}_{2}$ would be expected to be greater than those with $\mathrm{NO}_{2}$. In fact, the relationship was just the opposite. In a recent European study the concentrations of black smoke and $\mathrm{NO}_{2}$, but not particles with a $50 \%$ cut-off aerodynamic diameter of $10 \mu \mathrm{m}$ (PM10) were shown to be lower on Sundays than on weekdays, indicating that PM10 is less dependent than black smoke on traffic emissions. Other fractions of particles may, however, be more strongly correlated than PM10 with $\mathrm{NO}_{2}$. The measurement path used was above roof level in an area with heavy traffic, where the levels during a previous comparison were shown to correspond to the concentrations at $4 \mathrm{~m}$ above ground at the central background site included in the urban monitoring network. 
Positive correlations between the daily frequency of adverse health effects and short-term variations in $\mathrm{NO}_{2}$ levels in ambient air have been reported in a number of studies. Positive correlations between daily asthma admissions and $\mathrm{NO}_{2}$ concentrations were found in studies from Barcelona [15], Helsinki [16] and Paris [17]. However, when the data from Helsinki were reanalysed using a more sophisticated statistical model, the correlation with $\mathrm{NO}_{2}$ did not remain [18]. Increased frequencies of emergency room attendances for asthma attacks in Oulu, Finland [19], and of children's visits to paediatricians or hospitals for croup symptoms (but not obstructive bronchitis) in five German communities [20] were also associated with measured levels of $\mathrm{NO}_{2}$. Decreased peak flow levels in a panel of Danish asthmatics [21] were associated with increased levels of $\mathrm{NO}_{2} . \mathrm{NO}_{2}$ was also found to have a significant impact on pulmonary function in Tucson asthmatics [22-24], and on asthma incidence in mildly asthmatic children in Paris [10]. Pulmonary function, but not respiratory symptoms, was associated with $\mathrm{NO}_{2}$ exposure among Dutch schoolchildren who performed 6-10 pulmonary function tests [25].

The frequency of reporting sore throat and coughing with phlegm in a diary study of student nurses [26] and the duration, but not the incidence, of respiratory symptoms in preschool children in two cities in Switzerland [27] was associated with the levels of $\mathrm{NO}_{2}$. Total mortality in Los Angeles [28] and mortality among the elderly during the summer in Barcelona [29], were also associated with the fluctuations in $\mathrm{NO}_{2}$ concentrations. Moreover, in a metaanalysis using data from six cities in central and southern Europe, total (nonexternal) mortality was associated with daily levels of $\mathrm{NO}_{2}$ [30].

This study adds to the positive findings cited above. Only in Oulu was the $\mathrm{NO}_{2}$ concentration lower than in this study. Together, these results suggest that the occurrence of acute symptoms among asthmatics is related to daily variations in air quality, as indicated by ambient levels of $\mathrm{NO}_{2}$. There are, however, large variations in the control for effects of other pollutants in these studies. A synthesis of epidemiological evidence would also show many negative findings concerning the role of $\mathrm{NO}_{2}$ [2], whereas short-term effects of common levels of ambient air pollution have mostly been explained by variations in the levels of ozone, particulates or $\mathrm{SO}_{2}$ [31]. However, in another Swedish study, correlations were demonstrated between respiratory symptoms in symptomatic adults and daily variations in relatively low concentrations of $\mathrm{NO}_{2}$ [32]. In addition, in a Swedish cross-sectional study with population samples from 55 towns and cities, annoyance reactions [33] as well as frequent respiratory symptoms [11] were associated with six-monthly average concentrations of $\mathrm{NO}_{2}$, while $\mathrm{NO}_{2}$ was nonsignificant in a similar diary study from Piteå [8]. However, the $\mathrm{NO}_{2}$ concentration was 1.5 -fold higher in Landskrona than in Piteå. It is worthy noting that these Swedish studies were all conducted in areas where local sources of pollution other than motor vehicles are negligible, levels of $\mathrm{SO}_{2}$ and particulates are generally low and kerosene heaters or gas appliances are not used in homes. Respiratory effects related to ambient air pollutants should be easier to demonstrate in populations where other exposure is low both indoors and outdoors.

\section{References}

1. Sandström T. Respiratory effects of air pollutants; experimental studies in humans. Eur Respir J 1995; 8: 976995.

2. Lebowitz MD. Epidemiological studies of the respiratory effects of air pollution. Eur Respir J 1996; 9: 1029 1054.

3. Schwartz J, Wypij D, Dockery D, et al. Daily diaries of respiratory symptoms and air pollution: methodological issues and results. Environ Health Perspect 1991; 90: 180-187.

4. Dockery DW, Pope CA III. Acute respiratory effects of particulate air pollution. Annu Rev Public Health 1994; 15: 102-132.

5. Whittemore AS, Korn EL. Asthma and air pollution in the Los Angeles area. Am J Public Health 1980; 70: 687696.

6. Pope CA III, Dockery DW, Spengler JD, Raizenne ME. Respiratory health and PM10 pollution. A daily time series analysis. Am Rev Respir Dis 1991; 144: 668-674.

7. Silverman F, Hosein HR, Corey P, Holton S, Tarlo SM. Effects of particulate matter exposure and medication use on asthmatics. Arch Environ Health 1992; 47: 51-56.

8. Forsberg B, Stjernberg N, Falk M, Lundbäck B, Wall S. Air pollution levels, meteorological conditions and asthma symptoms. Eur Respir J 1993; 6: 1109-1115.

9. Peters A, Dockery DW, Heinrich J, Wichmann HE. Short-term effects of particulate air pollution on respiratory morbidity in asthmatic children. Eur Respir J 1997; 10: $872-879$.

10. Segala C, Fauroux B, Just J, Pascual L, Grimfeld A, Neukirch F. Short-term effect of winter air pollution on respiratory health of asthmatic children in Paris. Eur Respir $J$ 1998; 11: 677-685.

11. Forsberg B, Stjernberg N, Wall S. Prevalence of respiratory and hyperreactivity symptoms in relation to levels of criteria air pollutants in Sweden. Eur J Public Health 1997; 7: 291-296.

12. Platt U, Perner D. Direct measurement of atmospheric $\mathrm{CH}_{2} \mathrm{O}, \mathrm{HNO}_{2}, \mathrm{O}_{3}, \mathrm{NO}_{2}$ and $\mathrm{SO}_{2}$ by differential absorption in the near LTV. J Geophys Res 1980; 85: 7453-7458.

13. Melia JW, Florey Cdu V, Schinn S, Goldstein BD, Brooks AJF, John HH. The relation between indoor air pollution from nitrogen dioxide and respiratory illness in primary schoolchildren. Clin Respir Physiol 1980; 16: 7-8.

14. Hoek G, Brunekreef B. Effects of low level winter air pollution on respiratory health of Dutch children. Environ Res 1994; 64: 136-150.

15. Castellsagué J, Sunyer J, Sáez M, Antó JM. Short term association of urban air pollution with emergency room visits for asthma. Thorax 1985; 50: 1051-1056.

16. Pönkä A. Asthma and low level air pollution in Helsinki. Arch Environ Health 1991; 46: 262-270.

17. Dab W, Medina S, Quénel P, et al. Short term respiratory health effects of ambient air pollution: results of the APHEA project in Paris. J Epidemiol Comm Health 1996; 50: Suppl. 1, 42-46.

18. Pönkä A, Virtanen M. Asthma and ambient air pollution in Helsinki. J Epidemiol Comm Health 1996; 50: Suppl. 1, 59-62.

19. Rossi OVJ, Kinnula VL, Tienari J, Huhti E. Association of severe asthma attacks with weather, pollen, and air pollutants. Thorax 1993; 48: 244-248.

20. Schwartz J, Spix C, Wichmann HE, Malin E. Air pollution 
and acute respiratory illness in five German communities. Environ Res 1991; 56: 1-14.

21. Moseholm L, Taudorf E, Frosig A. Pulmonary function changes in asthmatics associated with low-level $\mathrm{SO}_{2}$ and $\mathrm{NO}_{2}$ air pollution, weather, and medicine intake; an 8 month prospective study. Allergy 1993; 48: 334- 344.

22. Lebowitz MD, Holberg CJ, Boyer B, Hayes C. Respiratory symptoms and peak flow associated with indoor and out-door air pollutants in the Southwest. JAPCA 1985; 35: 1154-1148.

23. Lebowitz MD, Collins L, Holberg C. Time series analysis of respiratory responses to indoor and outdoor environmental phenomena. Environ Res 1987; 43: 332341.

24. Quackenboss JJ, Krzyzanowski M, Lebowitz MD. Exposure assessment approaches to evaluate respiratory health effects of particulate matter and nitrogen dioxide. $J$ Exp Anal Environ Epidemiol 1991; 1: 83-107.

25. Hoek G, Meijer R, Scholten A, Noij D, Lebret E. The relationship between indoor nitrogen dioxide concentration levels and personal exposure: a pilot study. Int Arch Occup Environ Health 1984; 55: 73-78.

26. Schwartz J, Zeger S. Passive smoking, air pollution, and acute respiratory symptoms in a diary study of student nurses. Am Rev Respir Dis 1990; 141: 62-67.
27. Braun-Fahrländer C, Ackermann-Liebrich U, Schwartz J, Gnehm HP, Rutishauser M, Wanner HU. Air pollution and respiratory symptoms in preschool children. Am Rev Respir Dis 1992; 145: 42-47.

28. Kinney PL, Ozkanyak H. Associations of daily mortality and air pollution in Los Angeles County. Environ Res 1991; 54: 99-120.

29. Sunyer J, Castellsagué J, Sáez M, Tobias A, Antó JM. Air pollution and mortality in Barcelona. J Epidemiol Comm Health 1996; 50: Suppl. 1, 76-80.

30. Touloumi G, Katsouyanni K, Zmirou D, et al. Short-term effects of ambient oxidant exposure on mortality: a combined analysis within the APHEA project. Am J Epidemiol 1997; 146: 177-185.

31. Brunekreef B, Dockery DW, Krzyzanowski M. Epidemiologic studies on short-term effects of low levels of major ambient air pollution components. Environ Health Perspect 1995; 103: 3-13.

32. Forsberg B, Stjernberg N. Air pollution levels and daily respiratory symptoms among symptomatic subjects. Eur Respir J 1993; 6: Suppl. 17, 345.

33. Forsberg B, Stjernberg N, Wall S. People can detect poor air quality well below guideline concentrations: a prevalence study of annoyance reactions and air pollution from traffic. Occup Environ Med 1997; 54: 44-48. 